\title{
Observation of ground motions of aftershocks of the 2007 Noto Hanto earthquake in Monzenmachi, the Wajima city, for estimation of site amplification
}

\author{
Hiroaki Yamanaka ${ }^{1}$, Kentaro Motoki $^{1}$, Nobuyuki Yamada ${ }^{2}$, Tatsuya Sugawara ${ }^{1}$, Yumi Mabuchi $^{1}$, and Kazuoh Seo ${ }^{1}$ \\ ${ }^{1}$ Interdisciplinary Graduate School of Science and Engineering, Tokyo Institute of Technology, \\ 4259 Nagatsuta, Midori-ku, Yokohama, Kanagawa 226-8503, Japan \\ ${ }^{2}$ Fukuoka University of Education, 1-1 Akamabunkyomachi, Munakata City, Fukuoka Prefecture 811-4192, Japan
}

(Received June 14, 2007; Revised June 26, 2008; Accepted July 1, 2008; Online published November 7, 2008)

\begin{abstract}
Heavy damage occurred in Monzenmachi, the Wajima city, in the northern part of the Noto peninsula during the 2007 Noto Hanto earthquake with an $M_{\mathrm{j}}$ of 6.9. The area is located along a river and sandwiched by mountains at the northern and southern ends of a Quaternary narrow valley $1-2 \mathrm{~km}$ wide. The seismic intensity observed in the area was 6 upper during the main shock. In this study, we conducted observations of ground motions during aftershocks in Monzenmachi to understand local site effects in the vicinity of the seismic intensity station. We installed 11 accelerometers in three areas of Monzenmachi, Hashiride, Touge, and Kuroshima. In each area, three or five stations were chosen for a deployment of a linear array across the areas with heavy damage. The analysis was performed using aftershock records observed during events with $M_{\mathrm{j}}$ of 2.3-4.4. The spectral ratio of records from the station near the seismic intensity station to a reference station on Tertiary layers shows a dominant peak at a period of $1 \mathrm{~s}$. We also found distinct peaks at periods of 0.4-0.7 s in the spectral ratios at the sites in the areas with heavy damage. In contrast, no dominant peaks were identified at the stations at the foot of the mountains. This clearly indicates that site amplification effects play an important role in defining the damage distribution in an area. Similar peaks were found in the $H / V$ spectra of microtremors at the aftershock observation sites, though the peak amplitudes of the microtremor $H / V$ s are smaller than those of the $S$-wave spectral ratios.
\end{abstract}

Key words: 2007 Noto Hanto earthquake, local site effect, amplification, aftershock observation, Wajima city, microtremors.

\section{Introduction}

Heavy damage occurred in cities and towns in the northern part of the Noto peninsula, Japan, during the 2007 Noto Hanto earthquake with an $M_{\mathrm{j}}$ of 6.9. In particular, many old wooden houses collapsed in the main part of Monzenmachi, the Wajima city in Ishikawa prefecture (e.g., Moroi et al., 2007). The area was located in the focal area of the earthquake, and the seismic intensity and the maximum ground acceleration determined from a seismic intensity meter at the city office in the town were 6 upper and $1.3 \mathrm{G}$, respectively, during the main shock (National Institute for Land and Infrastructure Management and Building Research Institute, 2007). Since recordings of the ground motion during the main shock at that site are not available, detailed features of the ground motion's characteristics in the area are still unknown. The area is located in a narrow valley about 1-2 km wide along the Hakka River. This geological setting suggests that local site amplification can play an important role in characterizing ground motion features in the area together with source rupture processes during the main shock.

In this study, we conducted observations of ground mo-

Copyright (c) The Society of Geomagnetism and Earth, Planetary and Space Sciences (SGEPSS); The Seismological Society of Japan; The Volcanological Society of Japan; The Geodetic Society of Japan; The Japanese Society for Planetary Sciences; TERRAPUB. tions during aftershocks of the 2007 Noto Hanto earthquake in Monzenmachi to estimate the site amplification and to provide basic data for understanding the characteristics of strong ground motion. In addition to the observations of earthquake ground motion, microtremor records were collected at the observation sites to investigate the relationship between spectral features of the earthquake ground motion and microtremors. We report the results of a preliminary analysis of the observed data.

\section{Observation}

The observations of ground motion during aftershocks were conducted in the three most heavily damaged areas in Monzenmachi of Hashiride, Touge, and Kuroshima. The Hashiride and Touge areas are sandwiched between mountains at the northern and the southern ends of the valley along the Hakka River, as shown in Fig. 1. The valley is covered with Quaternary soils over Tertiary rock that exists near the surface in the mountains (Editing Committee of Engineering Geological Map in Hokuriku District, 1990). The Kuroshima area is located in the Quaternary Terrace near the coast line.

We temporarily installed 11 accelerometers in three areas. Three or five stations were chosen in each area, as shown in Fig. 1. Three stations were established in the Hashiride area. The L1 station is located at the foot of 

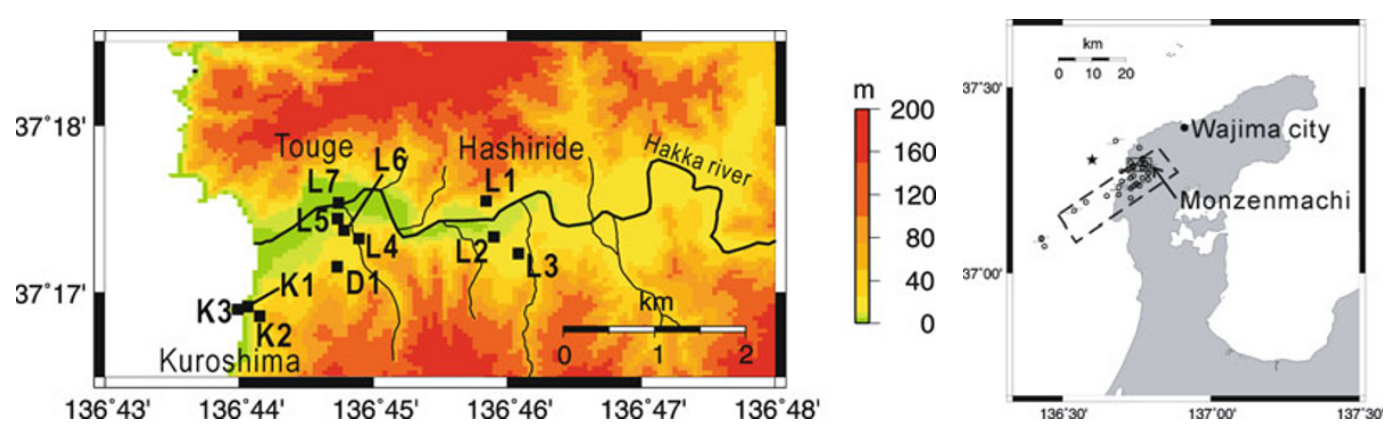

Fig. 1. Locations of observation stations are shown as squares (left). The enclosed area shown by a solid line in the right figure indicates the area mapped in the left figure. Circles in the right figure show locations of aftershocks used in this study. Area indicated with dash lines is fault plane by Aoi et al. (2007). Ground motions in Fig. 3 observed during an event are shown by a star in the right figure.

Table 1. Locations of observation stations.

\begin{tabular}{ccll}
\hline Site code & Location & Latitude & Longitude \\
\hline L1 & Hashiride & 37.29249 & 136.76404 \\
L2 & Hashiride & 37.2889 & 136.76501 \\
L3 & Hashiride & 37.28725 & 136.76804 \\
L4 & Touge & 37.28875 & 136.74826 \\
L5 & Touge & 37.29071 & 136.74559 \\
L6 & Touge & 37.28954 & 136.74637 \\
L7 & Touge & 37.29231 & 136.74569 \\
D1 & Touge & 37.28592 & 136.74554 \\
K1 & Kuroshima & 37.28103 & 136.73587 \\
K2 & Kuroshima & 37.28199 & 136.7344 \\
K3 & Kuroshima & 37.2817 & 136.7332 \\
\hline
\end{tabular}

the northern mountains, while L2 and L3 were deployed on Quaternary layers. L3 is located on a small fan caused by another river, at a slightly higher elevation than that of L2. The former station is closest to the location of the seismic intensity-meter behind the city office in the heavily damaged area. A small number of wooden houses are around L2. Five stations were placed in the Touge area (L4-L7 and D1). The L4 station is located at the foot of the mountains at the southern end of the valley. This site is used as the reference station in the following analysis. The other three stations, L5, L6, and L7, are located on the Quaternary layers in the valley. The damage around stations L5 and L6 was heavy, while no houses exist around L7 near the river. Station D1 is on Terrace deposits that are classified by geological conditions different from the others in the Touge area. The Kuroshima area is characterized by a steep slope from the coast line. Station K3 is located near the coast, while $\mathrm{K} 2$ is located at an elevation of about $20 \mathrm{~m}$ almost on the top of the cliff. Station K1 is situated on a slope in the heavily damaged area. Stations K2 and D1 are located in cemeteries where approximately $90 \%$ and $20 \%$ of tombstones were overturned, respectively (Moroi et al., 2007). The locations of the stations are tabulated in Table 1.

A three-component accelerometer and a 24 bit-digital recorder were temporarily installed on the surface or on a basement floor of a building at each station. The instruments were continuously battery-operated, and recorder timing was corrected with a GPS signal. Continuous records of ground acceleration were stored at a sampling interval of $0.01 \mathrm{~s}$ in the recorder. Observations began in the afternoon on the 28 March 2007. At the 3 stations in the Kuroshima area and D1, observations were terminated on $31 \mathrm{March}$; those at the other 7 stations were continued until 11 April. We also obtained a 5 min recording of threecomponents of microtremors at each site using a sensitive seismometer.

\section{Analysis of Aftershock Records}

Aftershock records with high signal-to-noise ratios were selected for the following analysis. The magnitudes of the selected events are between 2.6 and 4.4 on the Japan Meteorological Agency scale, as shown in Fig. 2. The hypocentral distances of the stations for the events are also displayed in the figure with peak ground accelerations (PGAs) of the observed records. Most of the PGAs are less than $50 \mathrm{~cm} \mathrm{~s}^{-2}$. The maximum PGA is $96 \mathrm{~cm} \mathrm{~s}^{-2}$ with a corresponding peak velocity of $2.9 \mathrm{~cm} \mathrm{~s}^{-1}$. We therefore discuss the spectral characteristics of site effects during weak shaking in this study. The epicenters of the events are shown in Fig. 1, together with the fault plane for the main shock as determined by Aoi et al. (2007).

Ground velocities integrated from acceleration records for one of the events with an $M_{\mathrm{j}}$ of 3.7 are displayed in Fig. 3. The velocities in the figure were filtered with a highpass filter having a cut-off frequency of $0.5 \mathrm{~Hz}$. The lowfrequency later phases are dominant in ground motions at stations L2, L3, L5, and L7, while the ground motions at L1 and L4 are small and simple, mainly containing only initial $P$ - and $S$-waves. Most of the stations with distinct later phases are in the heavily damaged parts of the town. We compared the peak ground velocity (PGV) of the aftershock records. Figure 4 shows the average ratios of the PGVs all the stations to those at the reference station L4. The PGV ratios at $\mathrm{L} 2, \mathrm{~L} 3, \mathrm{~L} 7$, and $\mathrm{K} 1$ are larger than 2, and those for the other sites are between 1 and 2 .

We next calculated ratios of the horizontal spectra of the $S$-wave parts of the records at the stations to those at the reference station. A horizontal spectrum was calculated from the root-mean-square of two horizontal motions for each event. The ratios of the horizontal spectra for all events were then averaged. It is noted that spectra for L4 have no distinct trough in the time period of interest in this study. The ratios are compared in Fig. 5. The spectral ratios in this figure can be classified into three types. The spectral ra- 

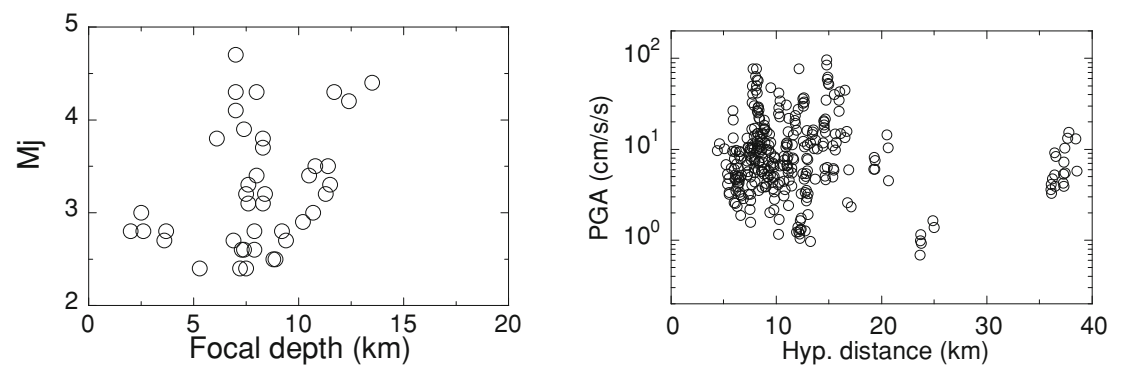

Fig. 2. Relationship between $M_{\mathrm{j}}$ and focal depth (left) for aftershocks used in this study, and hypocentral distances and peak ground acceleration at each site (right).
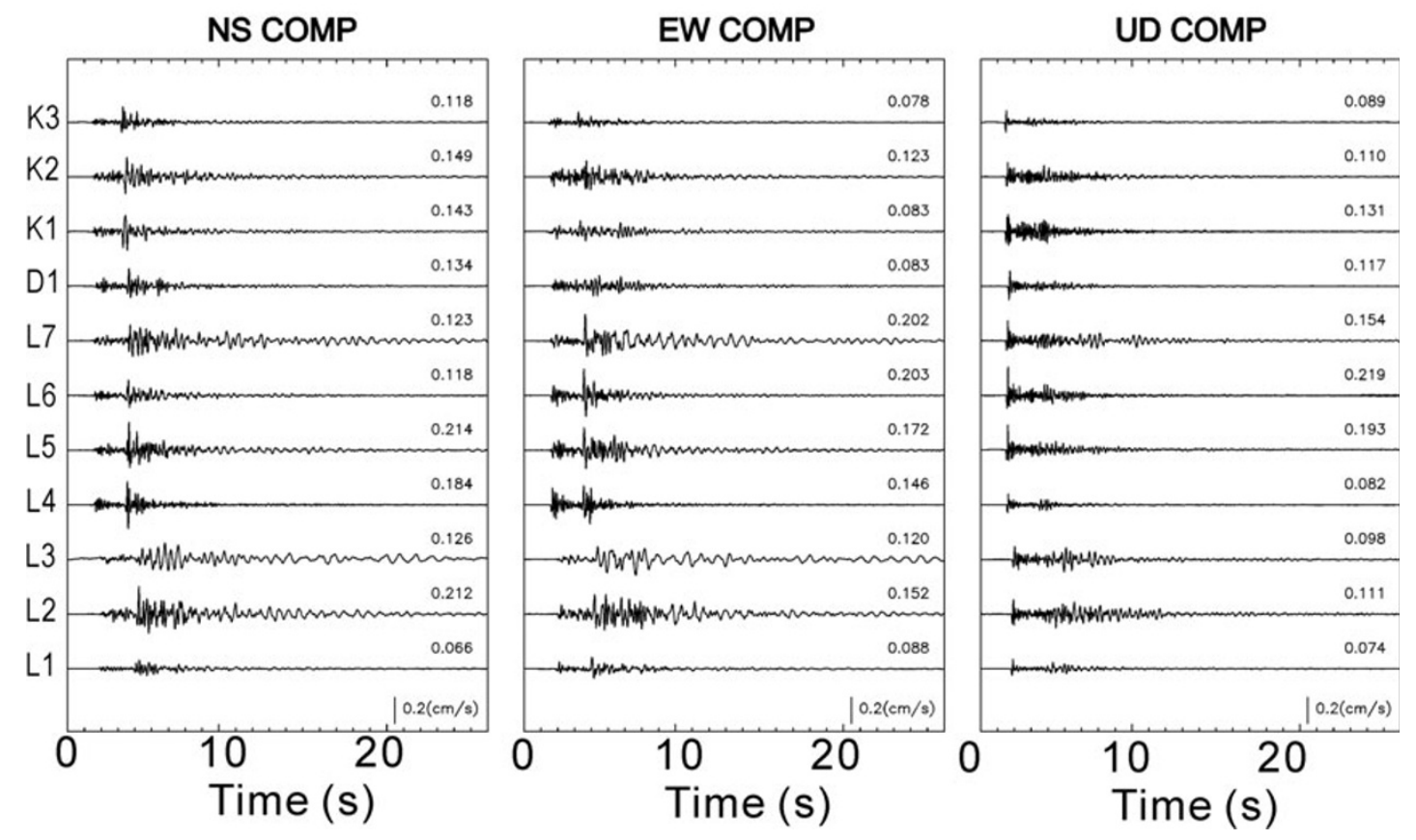

Fig. 3. Ground velocities of aftershock with an $M_{\mathrm{j}}$ of 3.7 and depth of $8.3 \mathrm{~km}$. North-south (left), east-west (middle), and vertical (right) components are displayed. Each trace was calculated from the integration of acceleration record after filtering with a high-pass filter having a cut-off frequency of $0.5 \mathrm{~Hz}$.

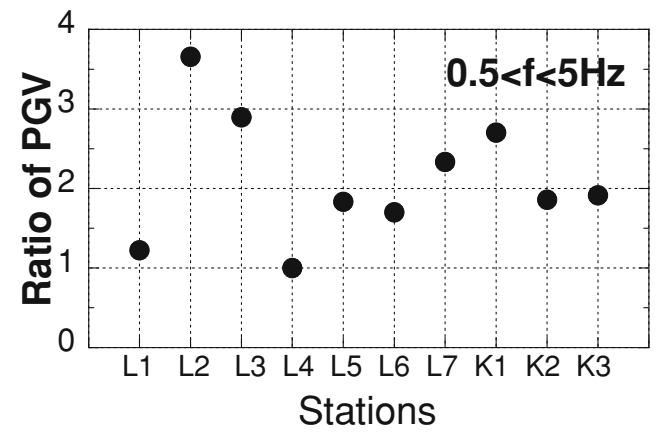

Fig. 4. Distribution of average ratios of peak ground velocities of all the aftershocks. The peak velocities were calculated with band-pass filtering at a frequency of $0.5-5 \mathrm{~Hz}$.

tio at the station near the city office (L3) shows a dominant peak at a period of $1 \mathrm{~s}$. Since the spectral peak is so dominant at a single period, the subsurface structure at the site is likely to be very simple, with a high velocity contrast. This strong amplification at this frequency range may be one of the major reasons for the large peak acceleration at the station. Similar dominant spectral peaks can be identified in the ratios for L2, L7, and K2, but with slightly shorter dominant periods than that of L3. The second classification of the spectral ratio is marked by slightly smaller and broader peaks at periods of $0.4-0.7 \mathrm{~s}$ as in the spectral ratios at L5, L6, D1, and K1. The sites of the first two classification types are located in the heavily damaged areas, except for L2, L7, and D1, where only a small number of old wooden houses exists. Yoshimi et al. (2007) also reported similar features of ground motion during aftershocks at sites near our stations. The different ratios at D1 and K2 can quantitatively explain the differences in the ratios of the overturned tombstones near the sites. No dominant peaks were identified at station L1 near the mountains or at K3 near the coast. Since the spacing between these stations is very small, the local site effects are likely the reason for the differences in the spectral ratios. The variation in the ratios also indicates that such site amplification effects must be sufficiently included in a study aimed at understanding the damage distribution in the area. 

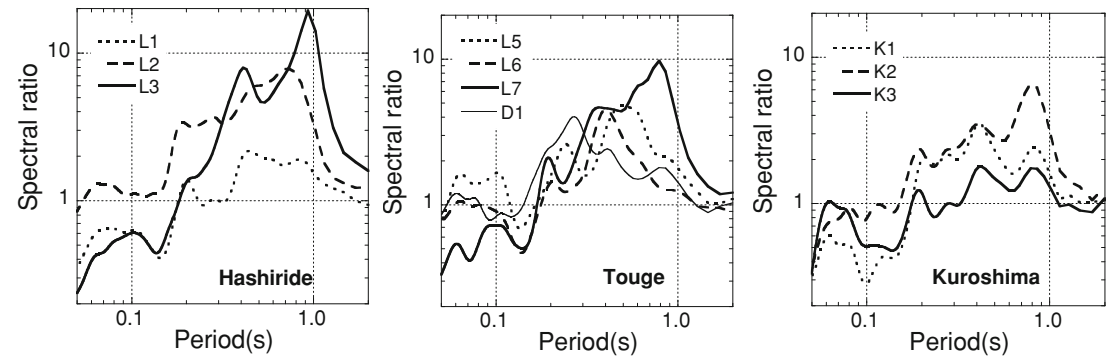

Fig. 5. Ratios of $S$-wave spectra of aftershocks at stations in Hashiride (left), Touge (middle) and Kuroshima (right) to those at reference station of L4.
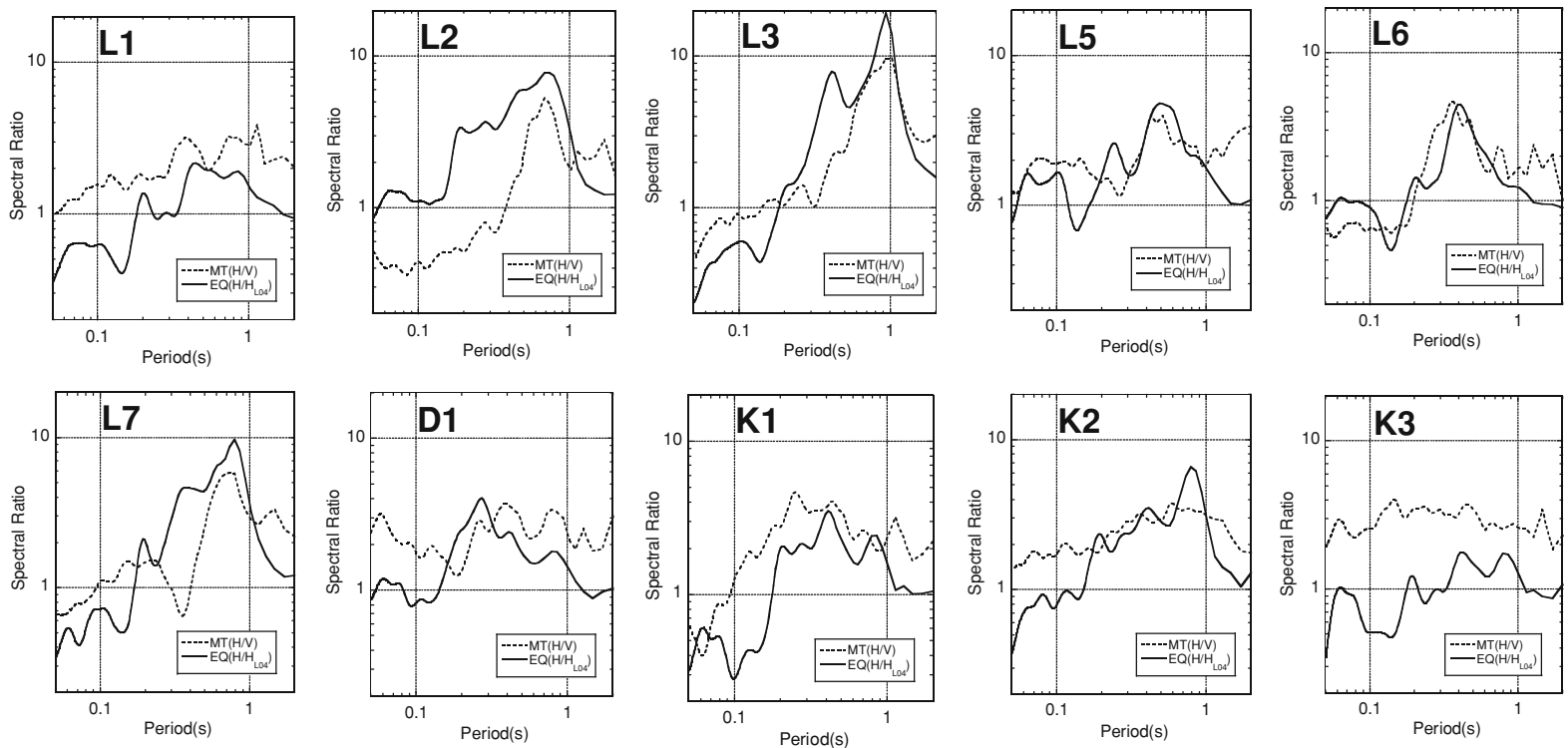

Fig. 6. Comparison of $S$-wave spectral ratios from aftershock records with horizontal-to-vertical ratios of microtremors shown by solid and broken lines, respectively.
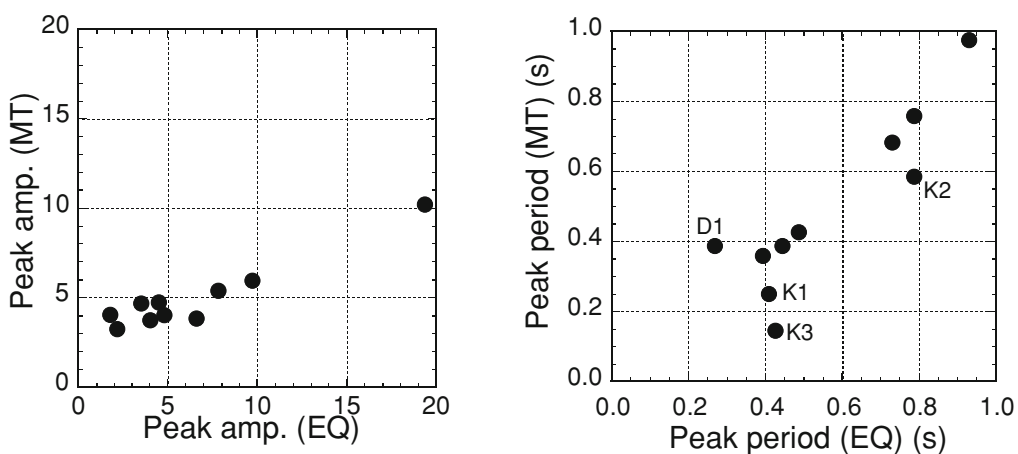

Fig. 7. Comparisons of peak periods (right) and peak amplitudes (left) between spectral ratios of $S$-waves in aftershocks and horizontal-to-vertical ratios of microtremors.

\section{Comparison of $S$-wave Spectral Ratios with Mi- crotremor $H / V S$}

We compared the spectral ratios derived from the aftershocks with horizontal-to-vertical ratios of microtremors $(H / V \mathrm{~s})$. Many previous studies have reported that microtremor $H / V$ s show similar spectral features as site amplification factors (e.g., Lermo and Chavez-Garcia, 1994; Nakamura, 1989). We therefore examined the applicability of the microtremor $H / V$ to assess site effects in this area.

Figure 6 compares of the spectral ratios from the aftershocks with the microtremor $H / V$ ratios at all sites. Mi- crotremor spectra were calculated from 20.48-s data for several segments of records, and all the spectra were averaged before calculating spectral ratio. The spectral shapes of the ratios for the aftershocks at most of the sites are significantly similar to those of the microtremor $H / V$ s. In particular, the dominant peak at a period of around $1 \mathrm{~s}$ in the aftershocks' spectral ratio at L3 is well explained by the microtremors. Miura and Midorikawa (2007) also pointed out a similar peak of microtremor $H / V \mathrm{~s}$ that appeared at the seismic intensity station. The peaks at $0.4-0.7$-s periods at the other sites are also in agreement with each other. The 
microtremor $H / V$ at $\mathrm{L} 1$ is relatively flat, without any dominant peaks, indicating no distinct local site effects.

We next compared the spectral features of the $H / V$ s with those estimated from the spectral ratios of the aftershocks. Figure 7 compares the periods and the amplitudes of peaks of the microtremor $\mathrm{H} / \mathrm{V} \mathrm{s}$ and the aftershock spectral ratios. The two kinds of the peak periods agree well with each other, except for stations D1, K1, K2, and K3, which are located on the Terrace deposits. This suggests that the amplification mechanisms in the Terrace deposits might be different from that in the Quaternary sedimentary layers in the valley. On the other hands, the amplitudes of the spectral ratios are twice those of the microtremor $H / V \mathrm{~s}$, as shown in the left graph of Fig. 7. However, they are linearly correlated and show one-to-one mapping. The comparisons indicated a high possibility of using microtremors to assess local site effects due to shallow soils in the area during an earthquake.

\section{Conclusions}

We conducted observations of ground motions during aftershocks of the 2007 Noto Hanto earthquake in Monzenmachi, the Wajima city in the Ishikawa prefecture to understand the effects of the local site amplifications. Accelerometers were temporarily installed at 11 sites in the town. We analyzed the variation among the local site amplifications in Quaternary soils using the spectral ratio of the aftershock records. The amplification at the seismic intensity station in the town was characterized by a significantly dominant peak at a period of $1 \mathrm{~s}$. Amplifications at the other sites in the damaged area also show dominant peaks, with periods ranging from 0.4 to $0.7 \mathrm{~s}$. No distinct peaks were identified in the spectral ratios at the observation site on Tertiary layers. We found that the peak periods of the $S$-wave spectral ratios from the aftershocks are identical to those of the horizontal-to-vertical ratios of microtremors, though the peak amplitudes of the microtremor $H / V$ s are smaller than those of the $S$-wave spectral ratios.
Acknowledgments. The comments from two reviewers are acknowledged to have improved the manuscript. We also thank those who allowed us to install the instruments during the observations of ground motions during aftershocks. This study was supported by a Grant-in-Aid for Special Purposes, the Special Coordination Funds titled Urgent research on the 2007 Noto Hanto Earthquake from the Ministry of Education, Culture, Sports, Science and Technology (MEXT), as well as a 21st Century Center of Excellence (COE) Program titled Evolution of Urban Earthquake Engineering from the MEXT. Some of the figures in this paper were produced using GMT (Wessel and Smith, 1991).

\section{References}

Aoi, S., H. Sekiguchi, N. Morikawa, S. Senna, and T. Kunugi, Ground motion and rupture process of the 2007 Noto Hanto earthquake inferred from strong motion data of K-NET and Kik-net, Abstracts of Japan Geoscience Union meeting 2007, Z255-P006, 2007.

Editing Committee of Engineering Geological Map in Hokuriku District, Engineering geological map of Hokuriku district 1:200,000, 1990.

Lermo, J. and F. J. Chavez-Garcia, Are microtremors useful in site response evaluation?, Bull. Seismol. Soc. Am., 84, 1350-1364, 1994.

Miura, H. and S. Midorikawa, Characteristics of microtremors on strong motion observation stations in the 2007 Noto-Hanto earthquake, $A b$ stracts of Japan Geoscience Union meeting 2007, Z255-P042, 2007.

Moroi, T., M. Kamata, T. Ikeda, and K. Kanda, Relationship between seismic intensity and regional damage due to the 2007 Noto Hanto earthquake, Abstracts of Japan Geoscience Union meeting 2007, Z255P043, 2007.

Nakamura, Y., A method for dynamic characteristics estimation of subsurface using microtremor on the ground surface, Q. Report of Railr. Tech. Res. Inst., 30, 25-33, 1989.

National Institute for Land and Infrastructure Manegement and Building Research Institute, Quick report of survey for the 2007 Noto Hanto earthquake ('07.3.26-27), http://www.kenken.go.jp/ japanese/contents/activities/other/disaster/jishin/2007noto/houkokusho/ 200704061600/index.pdf, 19, 2007.

Wessel, P. and W. H. F. Smith, Free software helps map and display data, EOS, Trans. AGU, 72, 441, 445-446, 1991.

Yoshimi, M., K. Yoshida, H. Sakamoto, and I. Cho, Temporal strong motion observation of aftershocks of the 2007 Noto Peninsula earthquake, Abstracts of Japan Geoscience Union meeting 2007, Z255-P037, 2007.

H. Yamanaka (e-mail: yamanaka@depe.titech.ac.jp), K. Motoki, N. Yamada, T. Sugawara, Y. Mabuchi, and K. Seo 